\title{
Palindromic rheumatism
}

\section{Clinical and immunological studies}

\author{
M. H. WILLIAMS,* P. J. H. S. SHELDON, † G. TORRIGIANI, V. EISEN, AND \\ S. MATTINGLY
}

Departments of Rheumatology Research, Rheumatology and Physical Medicine, and Immunology, Middlesex Hospital Medical School and Middlesex Hospital, London

Hench and Rosenberg (1944) described 34 patients with recurring episodes of arthritis and periarthritis usually lasting less than a week and named by them 'palindromio rheumatism'. The features they emphasized may be summarized as follows:

(1) Recurrent attacks of joint pain and swelling at variable and irregular intervals lasting a few hours or a few days.

(2) Any joint affected but especially fingers, wrists, shoulders and knees.

(3) Para-articular attacks and transient nodules.

(4) Good health: normal blood tests and $x$-rays.

(5) Good prognosis-no effective treatment.

Several case reports have appeared since then, though few series of patients have been followed up (Ward and Okihiro, 1959; Rotes Quérol and Lience, 1959; Dames and Zuckner, 1961; Ansell and Bywaters, 1959).

The main differential diagnosis is from crystal synovitis which may be due either to sodium urate or to calcium pyrophosphate. In these conditions, attacks are usually monarticular, occurring in favoured joints and frequently lasting for about a week. In those due to sodium urate, erosions may be detected, there is hyperuricaemia, and crystals of monosodium urate may be detected in tophi and synovial fluid. In those due to calcium pyrophosphate, calcification of articular cartilage may be seen, and the diagnosis is supported by the demonstration of calcium pyrophosphate crystals in synovial fluid; hyperuricaemia may or may not be associated.

Intermittent hydrarthrosis is a condition distinguished by the regularity of attacks, which nearly always affect one or both knees, though other joints may rarely be involved (Mattingly, 1957).

The differentiation of palindromic rheumatism from episodic rheumatoid arthritis is not easy, though Hench (1947) mentioned that the latter tended to occur in favoured joints, para-articular manifesta- tions were less frequent, and the finger pads were not involved. The duration of attacks was longer, intervals between attacks tended to be shorter, and there were often symptoms between attacks. The erythrocyte sedimentation rate was increased, and $x$ rays and joint biopsy showed changes characteristic of rheumatoid arthritis. Nevertheless, some authors have expressed the view that palindromic rheumatism is a variant of episodic rheumatoid arthritis or a stage in its development (Ansell and Bywaters, 1959; Robinson, 1963; Mattingly, 1966).

\section{Present investigations}

In an attempt to differentiate palindromic rheumatism from rheumatoid arthritis on an immunological basis, leucocyte migration inhibition and anti-IgG levels were estimated. The migration of leucooytes in the presence of Mycoplasma fermentans antigen has been shown to be inhibited in two-thirds of cases of seropositive rheumatoid arthritis (Williams, Brostoff, and Roitt, 1970) and anti-IgG levels were found to be raised in cases of seronegative rheumatoid arthritis (Torrigiani, Roitt, Lloyd, and Corbett, 1970). These studies were therefore carried out in the group of patients diagnosed clinically as having palindromic rheumatism and compared with results obtained in patients with rheumatoid arthritis.

Several cases featuring pain, swelling, and discoloration around joints were ascribed by Cohen (1911) to angioneurotic oedema. These he believed to be 'frequently mistaken for gout or rheumatism'. Patients with hereditary angioneurotic oedema have been shown to lack a component of the complement system-C'1 esterase inhibitor (Doraldson and Rosen, 1966). Webb (1970) described a patient in whom a diagnosis of palindromic rheumatism was entertained but who was subsequently shown to have hereditary angioneurotic oedema, confirmed by the absence of $C^{\prime} 1$ esterase inhibitor in the patient's

* Present address: Nuffield Unit of Medical Genetics, University of Liverpool.

+ Reprint requests: Dr. P. J. H. S. Sheldon, Department of Rheumatology and Physical Medicine, Middlesex Hospital, London, W1P 9PG.

Accepted for publication February 12, 1971. 
serum. In view of the possibility that the episodic nature of palindromic rheumatism may be regarded as a joint manifestation analogous to the skin and subcutaneous tissue phenomena seen in hereditary angioneurotic oedema, $\mathrm{C}^{\prime} 1$ esterase inhibitor was estimated in our series of patients.

\section{Patients studied}

35 patients (13 male and 22 female) with a diagnosis of palindromic rheumatism were investigated in the Department of Rheumatology and Physical Medicine of the Middlesex Hospital. The duration of history varied from $9 \mathrm{mths}$ to 23 yrs (mean $7 \cdot 4 \mathrm{yrs}$ ). The diagnostic criteria adopted were:

(1) Attacks of pain and swelling in any joint occurring at irregular intervals.

(2) The subsequent return of the state of that joint to its condition prior to the attack.

(3) Duration of symptoms of a few hours to a few days.

(4) The absence when the diagnosis was first made, of chronic arthropathy, subcutaneous nodules or erosions on $x$-ray.

(5) Serum uric acid less than $6.5 \mathrm{mg} / \mathrm{ml}$.

(6) The absence of calcification in articular cartilage.

\section{Material and methods}

\section{ANTIGLOBULINS}

Sera from patients were screened for the presence of antiglobulins (rheumatoid factor) using the latex test (Hyland, rheumatoid arthritic test latex-globulin reagent). The quantitative estimation of these antibodies was carried out as described by Torrigiani and others (1970), using horse immunoglobulin as antigen. The normal range was taken as 15 to $35 \mu \mathrm{g} . / \mathrm{ml}$.

\section{MYCOPLASMA ANTIGENS}

These were prepared as described previously (Williams and others, 1970). Briefly, the method involved growing Mycoplasma fermentans (P.G. 18) in standard liquid medium. Organisms were harvested from 5-litre cultures which had been incubated for $36 \mathrm{hrs}$. Cells were washed four times in $0 \cdot 2 \mathrm{M}$ phosphate buffer pH 7.2. Membranes were collected by centrifugation of cells which had been disrupted by hypotonic shock and sonication (Williams and Taylor-Robinson, 1967). The protein concentration of the membrane suspension was adjusted to approximately $10 \mathrm{mg} . / \mathrm{ml}$.

\section{LEUCOCYTE MIGRATION}

The method followed was that of Bendixen and Søborg (1969). This exploits the phenomenon that leucocytes from sensitized individuals do not migrate from a capillary tube in the presence of antigen as well as they do in its absence. Inhibition was considered to be significant when the area of migration was less than 80 per cent. of that seen in the control chambers lacking antigen.

C'1-ESTERASE

N-acetyl-L-tyrosine ethyl ester (ATEe; British Drug
Houses) was used and a 0.5 stock solution was prepared in 2-ethoxy-ethanol.

A human serum fraction rich in $C^{\prime} 1$ esterase was separated and activated by the method of Nelson (1965). Preparations containing 60 to $110 \mathrm{C}^{\prime} 1$ esterase units per $\mathrm{ml}$. were obtained (the hydrolysis of ATEe by one $\mathbf{C}^{\prime} 1$ esterase unit releases $33.3 \mathrm{n}$-mole of $\mathrm{H}+$ per minute: Levy and Lepow, 1959).

Serum levels of $C^{\prime} 1$ esterase inhibitor were measured by a modification of the method of Levy and Lepow (1959). Ten $\mu$ l. of serum were incubated with 4-5 units of \& $\mathrm{C}^{\prime} 1$ esterase in a Radiometer titration vessel for $3 \mathrm{~min}$. Saline and ATEe were then added and the hydrolysis of $0.025 \mathrm{M}$ ATEe, in a total volume of $2 \mathrm{ml}$. followed by continuous automatic titration with $5 \mathrm{mM} \mathrm{NaOH}$ at $37^{\circ} \mathrm{C}$. and $\mathrm{pH} 7 \cdot 2$. The protein concentration in the system was less than $1 \mathrm{mg} . / \mathrm{ml}$.; no buffer was added. With this method, values of $18-35$ inhibitor units $/ \mathrm{ml}$. W were found in normal sera (one inhibitor unit inhibits ten $C^{\prime} 1$ esterase units, i.e. the release of $333 \mathrm{n}$-mole of $\omega^{\prime}$ $\mathrm{H}+/$ min.: Levy and Lepow, 1959).

\section{Results}

CLINICAL FINDINGS

The ratio of females:males in the 35 patients was $\vec{v}$ 1 7:1 (compared with $3: 1$ for rheumatoid arthritisMiall, Ball, and Kellgren, 1958). Twelve patients gave a history of purely monarticular attacks, three of only polyarticular attacks, and sixteen of both. Included as polyarticular attacks were those cases in which subsiding inflammation in one joint was followed by the onset of inflammation in another. This could occur before the first joint had completely returned to its original state before the attack. In the remainder the patient was either unsure, or the question was omitted at the time of interview. The minimum duration of patients' attacks was $2 \mathrm{hrs}$, the longest being about 1 week.

The joints involved are depicted in Table I which shows that almost any joint may be affected. The upper limb was more commonly involved than the lower, the spine rarely.

Table I Joints involved at any time during course of $\frac{D}{2}$ disease in 35 patients with palindromic rheumatism

\begin{tabular}{lc}
\hline Joint & No. of patients \\
\cline { 2 - 2 } Temporo-mandibular & 7 \\
Shoulder & 23 \\
Elbow & 21 \\
Wrist & 29 \\
Carpus & 25 \\
Metacarpophalangeal & 25 \\
Proximal interphalangeal & 24 \\
Terminal interphalangeal & 13 \\
Spine & 4 \\
Hip & 14 \\
Knee & 26 \\
Ankle & 21 \\
Foot & 18 \\
Toe & 19 \\
\hline
\end{tabular}


The age at onset of symptoms is depicted in Fig. 1; most cases commenced in the fifth decade, and there was no difference between the sexes.

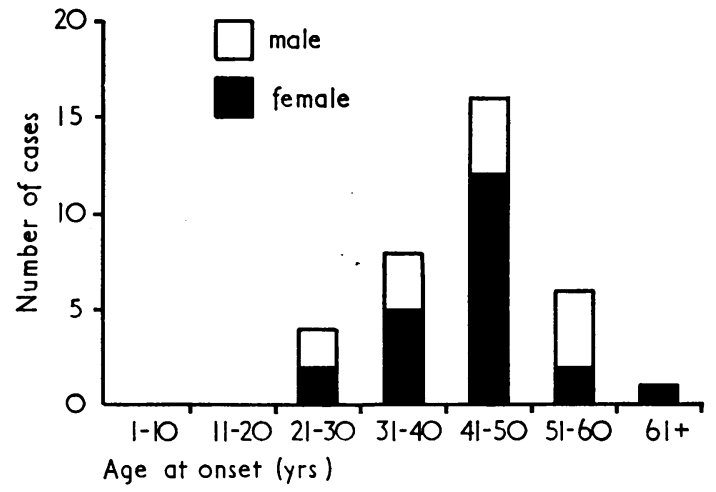

FIG. 1 Age at onset of palindromic rheumatism
Nineteen of the 35 patients had a low-grade arthropathy at the time of interview, and two were seen during an acute attack of palindromic rheumatism. In the latter, the joint was extremely tender with swelling and there was redness of the skin overlying the joint. These patients are distinguishable by an asterisk in Table II. Two males and one female had rheumatoid nodules at the time of examination. Sixteen cases had no arthropathy $3 \mathrm{mths}$ to $12 \mathrm{yrs}$ after onset of symptoms (mean 5.95 yrs). Of these, ten were female.

\section{INVESTIGATIONS}

Antiglobulins

The anti-IgG levels were found to be raised in all but one of the patients (Fig. 2, overleaf). Elevation of anti-IgG levels may be a reflection of a disorder of immune complexes. Similar values have been found

Table II Clinical and laboratory findings in 35 cases of palindromic rheumatism

\begin{tabular}{|c|c|c|c|c|c|c|c|c|}
\hline $\begin{array}{l}\text { Patient } \\
\text { No. }\end{array}$ & Sex & $\begin{array}{l}\text { Age at } \\
\text { onset } \\
\text { (yrs) }\end{array}$ & $\begin{array}{l}\text { Duration of } \\
\text { disease } \\
\text { when seen } \\
\text { (yrs) }\end{array}$ & $\begin{array}{l}\text { Arthropathy } \\
\text { at time of } \\
\text { review }\end{array}$ & $\begin{array}{l}\text { Leucocyte } \\
\text { migration } \dagger \\
\text { (per cent.) }\end{array}$ & $\begin{array}{l}\text { Anti-IgG } \\
\text { levels } \\
(\mu g . / m l .)\end{array}$ & $\begin{array}{l}\text { C'esterase } \\
\text { inhibitor } \\
\text { (units/ml.)§ }\end{array}$ & $\begin{array}{l}\text { Latex at } \\
\text { time of } \\
\text { review } \|\end{array}$ \\
\hline $\begin{array}{l}1 \\
2 \\
3 \\
4 \\
5 \\
6^{*} \\
7 \\
8 \\
9 \\
10 \\
11 \\
12 \\
13 \\
14 \\
15 \\
16 \\
17 \\
18 \\
19 \\
20 \\
21 \\
22\end{array}$ & $\mathbf{F}$ & $\begin{array}{l}27 \\
41 \\
39 \\
59 \\
38 \\
49 \\
49 \\
39 \\
49 \\
47 \\
42 \\
46 \\
46 \\
45 \\
56 \\
35 \\
45 \\
40 \\
49 \\
29 \\
48 \\
63\end{array}$ & $\begin{array}{c}4 \\
5 \\
5 \\
4 \\
10 \\
12 \\
4 \frac{1}{2} \\
5 \\
6 \\
11 \\
7 \\
2 \\
7 \\
9 \\
2 \frac{1}{2} \\
18 \\
6 \text { mths } \\
8 \\
12 \\
16 \\
8 \frac{1}{2} \\
3 \text { mths }\end{array}$ & $\begin{array}{l}+ \\
- \\
+ \\
+ \\
+ \\
= \\
- \\
+ \\
+ \\
- \\
\overline{+} \\
+ \\
+ \\
+ \\
+ \\
+\end{array}$ & $\begin{array}{l}59 \\
80 \\
50 \\
64 \\
53 \\
50 \\
68 \\
85 \\
83 \\
75 \\
52 \\
58 \\
65 \\
81 \\
78 \\
93 \\
84 \\
78 \\
87 \\
68 \\
88 \\
35\end{array}$ & $\begin{array}{r}93 \\
61 \\
74 \\
74 \\
74 \\
61 \\
94 \\
72 \\
58 \\
105 \\
95 \\
65 \\
53 \\
61 \\
175 \\
76 \\
81 \\
95 \\
61 \\
150 \\
174 \\
220\end{array}$ & $\begin{array}{l}18 \cdot 3 \\
14 \cdot 4 \\
14 \cdot 8 \\
18 \cdot 6 \\
19 \cdot 6 \\
32 \cdot 5 \\
36 \\
42 \\
26 \cdot 2 \\
33 \\
25 \cdot 3 \\
26 \cdot 4 \\
15 \cdot 9 \\
24 \cdot 3 \\
25 \\
30 \\
22 \cdot 3 \\
22 \cdot 3 \\
27 \cdot 6 \\
33 \\
27 \cdot 1 \\
18 \cdot 3\end{array}$ & $\begin{array}{r}\text { weak }+ \\
+ \\
\text { weak } \\
\text { weak }+ \\
+ \\
+ \\
+ \\
\text { weak }+ \\
\text { weak }+ \\
+ \\
+ \\
+ \\
+ \\
+ \\
+ \\
+ \\
\text { weak } \\
+ \\
\text { weak } \\
+ \\
+ \\
+ \\
+ \\
+\end{array}$ \\
\hline $\begin{array}{l}23 * \\
24 \\
25 \\
26 \\
27 \\
28 \\
29 \\
30 \\
31 \\
32 \\
33 \\
34 \\
35\end{array}$ & $\mathbf{M}$ & $\begin{array}{l}53 \\
57 \\
57 \\
43 \\
31 \\
39 \\
32 \\
55 \\
43 \\
44 \\
46 \\
29 \\
22\end{array}$ & $\begin{array}{c}9 \text { mths } \\
10 \text { mths } \\
4 \\
4 \\
4 \frac{1}{2} \\
4 \frac{1}{2} \\
6 \\
6 \\
7 \\
8 \\
11 \\
4 \\
23\end{array}$ & $\begin{array}{l}+ \\
+ \\
+ \\
- \\
+ \\
- \\
+ \\
\frac{+}{-} \\
+\end{array}$ & $\begin{array}{l}43 \\
37 \\
63 \\
60 \\
57 \\
63 \\
79 \\
93 \\
56 \\
40 \\
87 \\
66 \\
24\end{array}$ & $\begin{array}{l}47 \\
48 \\
93 \\
61 \\
69 \\
88 \\
57 \\
88 \\
72 \\
72 \\
88 \\
15 \\
74\end{array}$ & $\begin{array}{l}20 \cdot 2 \\
23 \cdot 1 \\
17 \cdot 1 \\
24 \cdot 1 \\
14 \cdot 8 \\
21 \cdot 3 \\
18 \cdot 6 \\
19 \cdot 2 \\
30 \cdot 3 \\
14 \cdot 7 \\
20 \cdot 8 \\
21 \cdot 3 \\
16 \cdot 8\end{array}$ & $\begin{array}{r}\text { weak }+ \\
\text { weak } \\
+ \\
+ \\
+ \\
+ \\
+ \\
+ \\
+ \\
\text { weak } \\
+ \\
+ \\
+\end{array}$ \\
\hline
\end{tabular}


in Still's disease (Torrigiani, Ansell, Chown, and Roitt, 1969), seronegative rheumatoid arthritis (Torrigiani and Roitt, 1967), and procainamideinduced systemic lupus erythematosus (Sheldon and Williams, 1970).

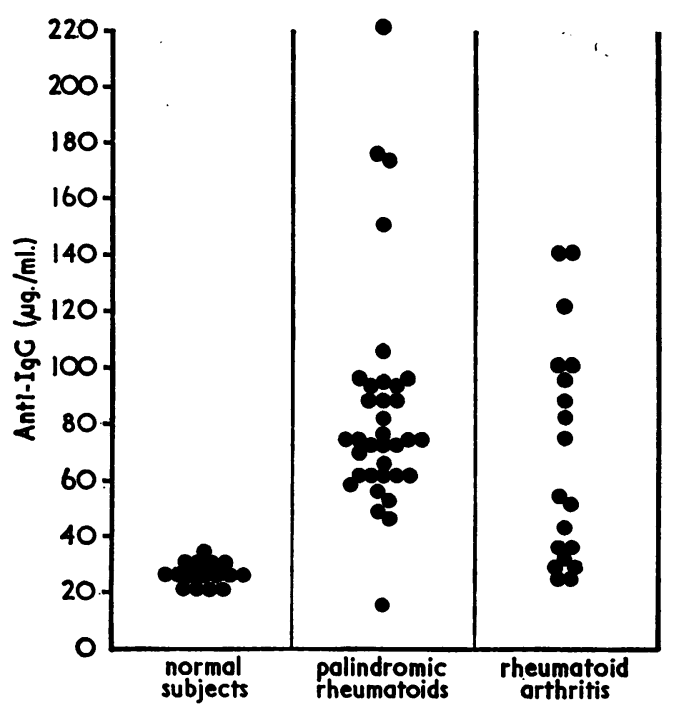

FIG. 2 Anti-IgG levels in 35 cases of palindromic rheumatism compared with nineteen cases of rheumatoid arthritis and sixteen controls

\section{Rheumatoid factor}

In 23 patients ( 15 females and 8 males), the original result of rheumatoid factor estimation was known. The subsequent course of these patients is depicted in Fig. 3.

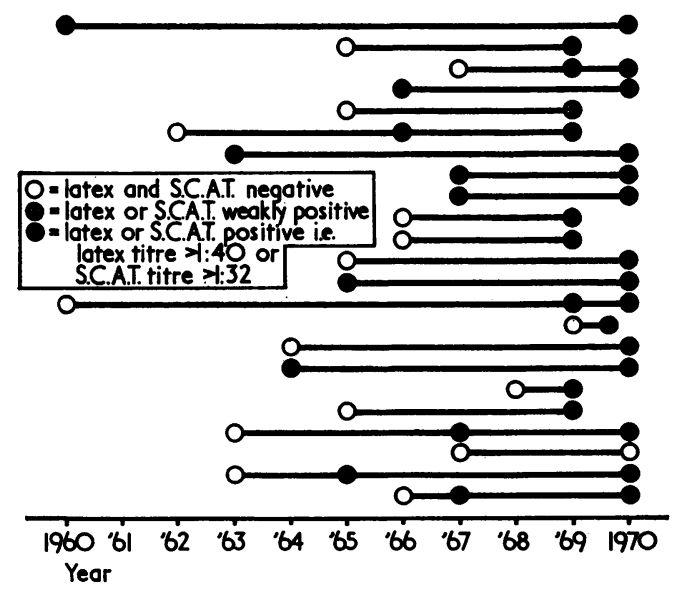

FIG. 3 Results of rheumatoid factor test in 23 patients with palindromic rheumatism

Of the fifteen females, three remained seropositive, and six converted from seronegative to seropositive, one from seropositive to weakly positive, and five from seronegative to weakly positive.
Of the eight males, two remained seropositive and one seronegative, and three converted from seronegative to seropositive, and two from seronegative to weakly positive.

\section{Leucocyte migration inhibition}

In the presence of Mycoplasma fermentans antigen this test was unequivocally positive in $\mathbf{2 5}$ of the 35 patients with palindromic rheumatism (i.e. 71 per cent.). These results are shown in Fig. 4 and are compared with the previously published results obtained with comparable groups of seropositive rheumatoid arthritics and normal healthy subjects (Williams and others, 1970).

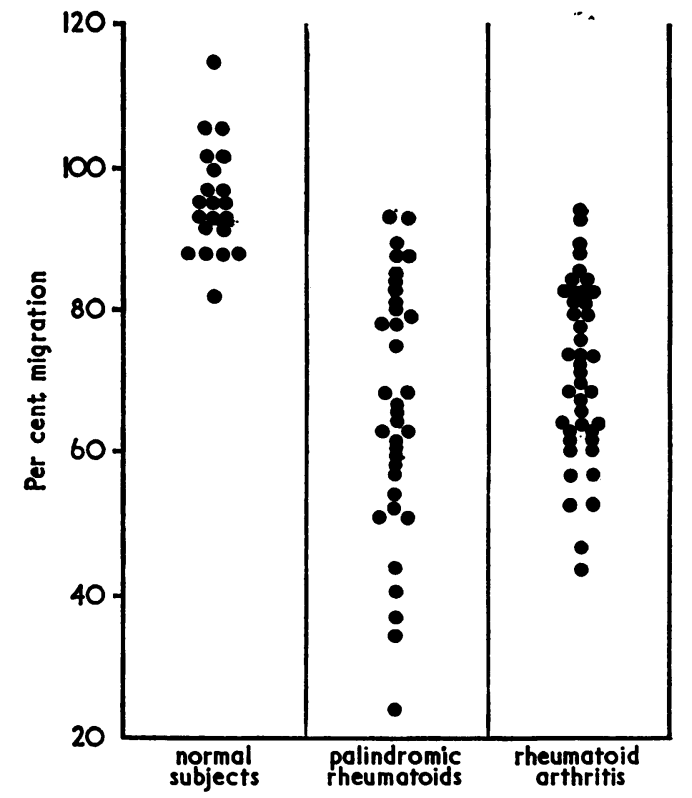

F,G. 4 Leucocyte migration results in 35 cases of palindromic rheumatism compared with 42 cases of rheumatoid arthritis and 21 controls

\section{$C^{\prime} 1$ esterase}

The patients were not deficient in $C^{\prime} 1$ esterase inhibitor, although fairly low levels were found in seven out of 35 sera (Table II).

\section{Discussion}

The clinical impression gained when examining the patients was that just over half (19 of 35) were indistinguishable from patients with low-grade rheumatoid arthritis. However, sixteen patients had no arthropathy when seen, 3 mths to 12 yrs (mean $5.9 \mathrm{yrs}$ ) after the commencement of symptoms. Of these only two remained seronegative.

Serum levels of $C^{\prime} 1$ esterase inhibitor showed no significant aberration in any of the patients.

Leuoocyte migration inhibition in the presence of 
Mycoplasma fermentans antigen was similar in the groups irrespective of the presence of arthropathy and resembled the results obtained in rheumatoid arthritis. This also applied to the IgG antiglobulin estimations, and suggests that, in these two respects, the patients with palindromic attacks were indistinguishable from those with rheumatoid arthritis. No correlation was found between antiglobulin levels and the degree of leucocyte migration inhibition in the presence of Mycoplasma fermentans antigen $(r=0.03)$. The elevated level of anti-IgG may arise in two ways:

(1) Nonspecific immunoglobulin is bound to the membrane of Mycoplasma fermentans, is thereby denatured and becomes antigenic (Williams and others, 1970).

(2) Specific antibody to Mycoplasma fermentans undergoes conformational change, resulting in the formation of a new antigen, thus stimulating the production of antiglobulin.

The inhibition of leucocyte migration may indicate a state of cell mediated (delayed type) hypersensitivity (Williams and others, 1970) to Mycoplasma fermentans antigen.

\section{Summary}

(1) 35 patients diagnosed initially as having palindromic rheumatism were reviewed olinically and immunologically at a mean of $7 \cdot 4 \mathrm{yrs}$ after the onset of symptoms.

(2) On clinioal grounds nineteen appeared to have developed a low-grade rheumatoid arthritis. Sixteen, however, had no arthropathy.

(3) Serum anti-IgG levels were raised in 34 cases, the results being similar to those found in seronegative rheumatoid arthritis.

(4) The leucocyte migration inhibition test in the presence of Mycoplasma fermentans antigen was positive in 25 cases, the results being similar to those found in rheumatoid arthritis.

(5) Serum levels of C'esterase inhibitor were normal in 28 cases, the remainder being slightly, though not significantly, lower than normal.

(6) These observations provide further evidence for palindromic rheumatism being a prodromal or atypical presentation of rheumatoid arthritis, with an essentially benign prognosis.

We wish to thank Dr. A. C. Boyle and Dr. Mary Corbett for allowing us to carry out these studies on patients under their care. We also thank Prof. C. A. Keele for his help and advice and Miss Norma Banks and Mr. R. Perry for their excellent technical assistance. The work was supported by grants from the Arthritis and Rheumatism Council, the Wates Foundation, and the Wellcome Trust.

\section{References}

Ansell, B. M., and Bywaters, E. G. L. (1959) Ann. rheum. Dis., 18, 331 (Palindromic rheumatism).

Bendixen, G., AND Søborg, M. (1969) Dan. med. Bull., 16, 1 (A leucocyte migration technique for in vitro detection of cellular-rapid delayed type-hypersensitivity in man).

CoHen, S. Solis (1911) Trans. Coll. Phys. Philadelphia, 3rd ser., 33, 309 (Certain angioneurotic manifestations in and around joints frequently mistaken for gout or rheumatism).

DAMES, R., AND ZUCKNER, J. (1961) Arch. interamer. Rheum., 4, 18 (Palindromic rhoumatism).

Donaldson, V. H., AND Rosen, F. S. (1966) Pediatrics, 37, 1017 (Hereditary angio-neurotic oedema-a clinica survey).

Hench, P. S. (1947) Arizona Med., 4, 62 (Arizona medical problems consultation and case analysis).

- AND Rosenberg, E. F. (1944) Arch. intern. Med., 73, 293 (Palindromic rheumatism, a new oft recurring disease of joints).

Levy, L. R., AND Lepow, I. H. (1959) Proc. Soc. exp. Biol. (N.Y.), 101, 608 (Assay and properties of serum inhibitors of $C^{\prime} 1$ esterase).

Matringly, S. (1957) Brit. med. J., 1, 139 (Intermittent hydrarthrosis). (1966) Ann. rheum. Dis., 25, 307 (Palindromic rheumatism).

Miall, W. E., Ball, J., AND Kellgren, J. H. (1958) Ibid., 17, 263 (Prevalence of rheumatoid arthritis in urban and rural populations in South Wales).

Nelson, R. A. (1965) 'The role of complement in immune phenomena', in 'The Inflammatory Process', ed. B. W. Zweifach, L. Grant, and R. T. McCluskey, p. 819 (1965) Academic Press, New York.

Robinson, W. D. (1963) In 'Cecil-Loeb Textbook of Medicine', 11th ed., ed. P. B. Beeson and W. McDermott, p. 1484. Saunders, Philadelphia. 
RotÉs QUEROL, J., AND LIENCE, E. (1959) Arch. interamer. Rheum., 2, 491 (Rheumatismos intermitentes). Sheldon, P. J. H. S., ANd Williams, W. R. (1970) Ann. rheum. Dis., 29, 236 (Procainamide-induced S.L.E.). Torrigiani, G., Ansell, B. M., Chown, E. E. A., AND Rortt, I. M. (1969) Ann. rheum. Dis., 28, 424 (Raised IgG antiglobulin factors in Still's disease).

- AND RorrT, I. M. (1967) Ibid., 26, 334 (Antiglobulin factors in sera from patients with rheumatoid arthritis and normal subjects).

- - - LlOYD, K. N., AND CoRBeTt, M. (1970) Lancet, 1, 14 (Elevated IgG antiglobulin in patients with sero-negative rheumatoid arthritis).

WARD, L. E., AND OKIHIRO, M. M. (1959) Quoted by R. W. Lamont-Havers (1960) In 'Arthritis and Allied Conditions', ed. J. L. Hollander, p. 708. Lea and Febiger, Philadelphia.

WebB, F. W. S. (1970) Proc. roy. Soc. Med., 63, 281 (Hereditary angio-oedema).

Williams, M. H., Brostoff, J., AND RorTt, I. M. (1970) Lancet, 2, 277 (Possible role of Mycoplasma fermentans in pathogenesis of rheumatoid arthritis).

- AND TAYLOR-Robinson, D. C. (1967) Nature (Lond.), 215, 973 (Antigenicity of mycoplasma membranes). 